\title{
Differential Expression of Receptor Tyrosine Kinases (RTKs) and IGF-I Pathway Activation in Human Uterine Leiomyomas
}

\author{
Linda Yu, Katrin Saile, Carol D Swartz, Hong He, Xiaolin Zheng, Grace E Kissling, Xudong Di, \\ Shantelle Lucas, Stanley J Robboy, and Darlene Dixon
}

Online address: http://www.molmed.org

doi: 10.2119/2007-00101.Erratum.Yu

Because of a production error, Figure 7 for this article was incorrectly presented in a recent issue (14[5-6]:264-275, MayJune 2008). A revised image appears to the right.

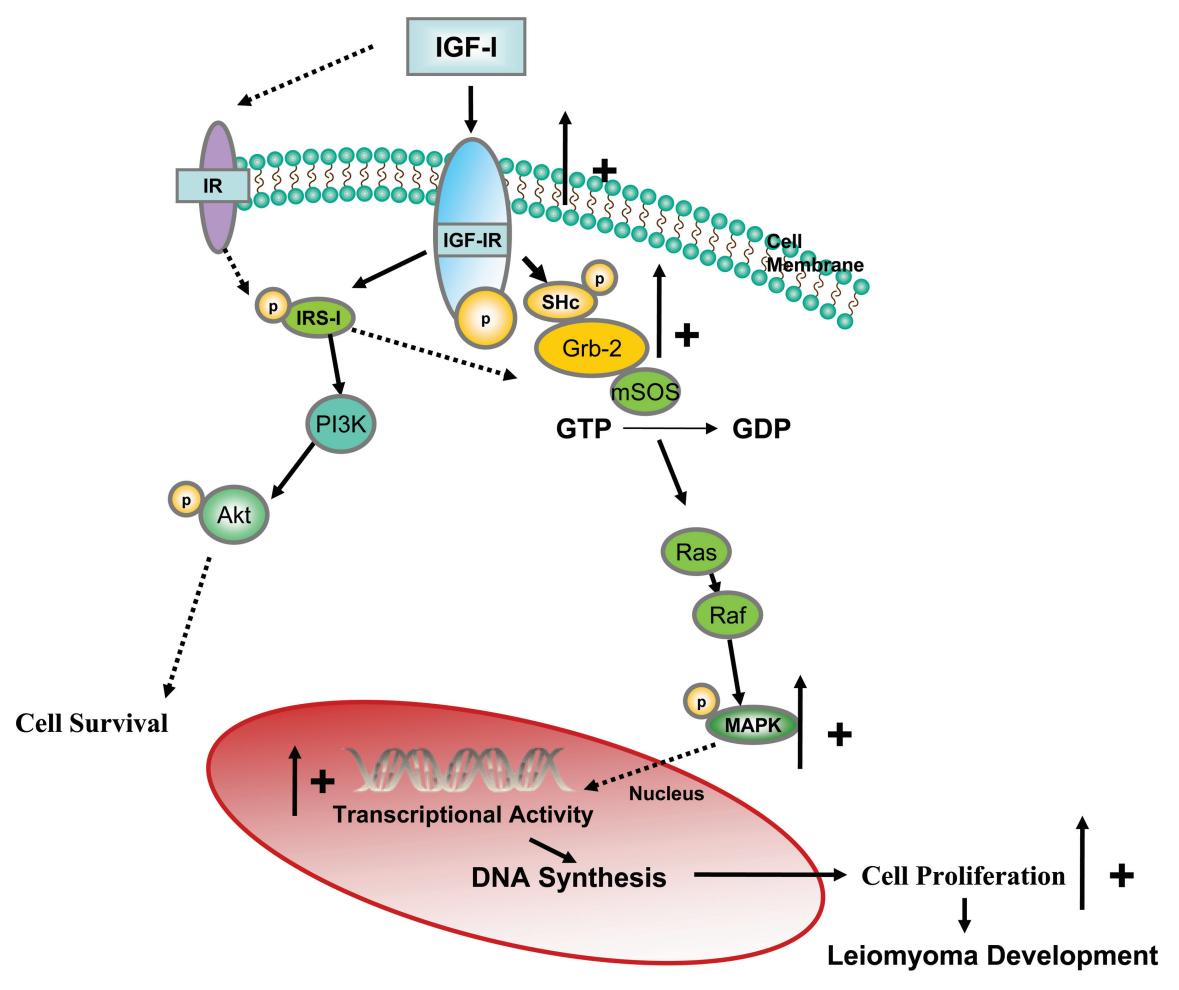

Figure 7. Proposed pathway.

In this model, IGF-I peptide binds to IGF-IR to induce tyrosine autophosphorylation and phosphorylation of its adaptor protein Shc. Phosphorylated Shc then is associated with the Grb2-mSOS complex to activate p21/Ras, which leads to proliferation by activation of the Ras/Raf/MAPK pathway. The IGF-I and IGF-IR complex also autophosphorylates its docking protein IRS-I, which, in turn, activates the survival PI3K/AKT pathway. However, on the basis of our studies, this pathway appears not to be playing a major role in leiomyoma growth. IRS-I also may recruit Grb2, but it appears that the Shc-Grb2 pathway is the predominant activator of $\mathrm{p} 21$ /Ras in IGF-IR signaling in UtLM cells and uterine leiomyoma tissue. 